\title{
In vitro regeneration and acclimatization of pineapple (Ananas comosus L. Merr. var. MD2)
}

\author{
${ }^{1}$ Ab Rahman, N.A., ${ }^{1}$ Abdul Latif, N., ${ }^{1}$ Udin, E. Z., ${ }^{1,2,3 *}$ Awal, A. and ${ }^{1,2}$ Shamsiah, A. \\ ${ }^{1}$ Faculty of Plantation and Agrotechnology, Universiti Teknologi MARA Melaka, Kampus Jasin, 77300 \\ Merlimau, Melaka, Malaysia. \\ ${ }^{2}$ Agricultural Biotechnology Research Interest Group, Faculty of Plantation and Agrotechnology, Universiti \\ Teknologi MARA Melaka, Kampus Jasin, 77300 Merlimau, Melaka, Malaysia. \\ ${ }^{3}$ Research and Innovation Division, Aras 3 Bangunan FF1, Universiti Teknologi MARA Selangor, Kampus \\ Puncak Alam, 42300 Bandar Puncak Alam, Selangor, Malaysia.
}

Article history:

Received: 22 July 2020

Received in revised form: 10

December 2020

Accepted: 17 January 2020

Available Online: 24 January 2021

Keywords:

Ananas comosus L Merr.

Pineapple,

In vitro regeneration,

Coconut water,

Acclimatization

DOI:

https://doi.org/10.26656/fr.2017.4(S5).010

\begin{abstract}
Ananas comosus L. Merr. is asexually propagated through the conventional method from its crowns, slips, hapas, and suckers. Plant tissue culture technique is applied for mass production of clonal pineapple within a shorter period compared to conventional propagation. Hence, this research aims to study the effect of coconut water and optimum sucrose concentration for in vitro growth performance of pineapple. In addition, this research also aims at optimizing the fertilization mechanism for the acclimatization of clonal pineapple ex vitro. The in vitro regeneration was performed by adding a different volume of coconut water and concentration of sucrose into the prepared culture media supplemented with $2.00 \mathrm{mg} / \mathrm{L}$ 6-Benzylaminopurine (BAP) and $1.00 \mathrm{mg} / \mathrm{L}$ Naphthaleneacetic acid (NAA). For acclimatization method, two different types of fertilizer served as treatments which were compound fertilizers (NPK 15:15:15) and controlled-release fertilizer (AJIB CRF, NPKMg 10:5:18:3). The planting media consisted of topsoil, sand, and compost composition in a ratio of 2:1:2. Results showed that culture media contained $20.00 \mathrm{~mL} / \mathrm{L}$ coconut water obtained the highest number of shoots (45.33 \pm 7.56). On the other hand, culture media supplemented with $30.00 \mathrm{~g} / \mathrm{L}$ sucrose concentration showed the highest number of shoots (47.25 \pm 10.81$)$. Meanwhile, the acclimatization method found that controlled-release fertilizer (AJIB CRF), NPKMg (10:5:18:3) showed about $90 \%$ of survival rate. The mean value for the number of leaves and leaves length $(\mathrm{cm})$ in acclimatized clonal pineapple using Controlled-release fertilizer (AJIB CRF) were 5.48 \pm 0.96 and $6.00 \pm 1.04$, respectively. Therefore, the addition of coconut water, optimum sucrose concentration, and the suitable type of fertilizer in both in vitro and ex vitro promote a better growth performance of clonal pineapple.
\end{abstract}

\section{Introduction}

Ananas comosus L. Merr. var. MD2 is a tropical fruit crop from Bromeliaceae family and an excellent fruit comes with juiciness, flavorful and valuable nutritional values including vitamin $\mathrm{C}$, potassium, calcium, crude fibre and carbohydrates (Hossain et al., 2015). In 2012, there were thousands of pineapples planted on 15,549 hectares' land in Malaysia with an estimated total production of 335,000 metric tons (Thalib et al., 2015). Due to that, pineapple var. MD2 has been selected as one of Malaysia's new ambitions in pineapple export as in 2011-2020 policy and identified to be a key crop under National Agrofood Policy. The development of pineapple production able to aids the economy by increasing income through increases in employment opportunities and foreign exchange (Hossain, 2016).

However, conventional propagation drew some limitations where the multiplication rate is slow, diseases transmission from the mother plant to the propagated plant as well as lack of uniformity where new planting material produced varied in the term of shape and size (Akin-idowu and Ibitoye, 2014). Limitations to healthy planting materials, including less uniformity, disease transmission, and insufficient planting materials caused difficulties for commercial growth (Mangesha et al., 2013). Plant tissue culture technique could be used as a 
solution to this problem as it could produce may pineapple plantlets (Hamid et al., 2013). Cloned pineapples (in vitro propagated) and plant that propagated traditionally have similar chemical and nutrient profiles, maturation period and physical properties. Thus, tissue culture may be a better alternative for the mass production of planting materials as they can survive under similar growing conditions as those propagated by traditional methods (Liu, 1989). Healthy clones could be initiated, and disease problem in seedlings could be overcome by using tissue culture techniques (Awal et al., 2011).

Coconut water is liquid obtained from the endosperm of the coconut while coconut milk is liquid obtained from the process of grating the endosperm flesh usually gotten from mature or old coconut. Coconut water has a low matter content with $2-5 \%$ wet basis mainly comprises of sugars and minerals. Besides the rich nutrient contains that beneficial for human, coconut water also possesses the ability to become a growth regulator to induce growth of tissue cultures (Yong et al., 2009). Coconut water has the presence of growth promoter factors such as cytokinins, a phytohormone that promotes cell division in roots and shoots and auxins the promotes shoot growth. Other phytohormones detected were ZMP (trans-zeatin riboside 5'- monophosphate), gibberellins ( $\mathrm{GA}_{1}$ and $\left.\mathrm{GA}_{3}\right)$, IAA (indole-3-acetic acid) and ABA (abscisic acid). The natural indole-3-acetic acid (IAA) present in coconut water can be used to induce the rooting process of Dracaena purplecompacta L (Agampodi, 2008). Other than that, coconut water can be used to substitute zeatin to induce plant cells to divide and grow rapidly as the liquid contains amino acids, organic acids, nucleic acids, vitamins, carbohydrates and plant regulators with high levels of zeatin and minerals (Peixe, 2007).

In addition, in vitro regeneration of pineapple has difficulty in executing the photosynthesis process due to several conditions including low intensity if light, lack of gas exchange and high air relative humidity. Sucrose is used as a carbon source for the in vitro regenerated plant to replace the carbon which the plant normally fixed from the atmosphere through photosynthesis (Sumaryono et al., 2012). The optimal concentration of sucrose in a medium should be allowed to satisfy the energy needed for cell growth and development without having any negative osmotic effect on shoot formation (Javed and Ikram, 2008).

Despite the advances obtained by micropropagation, there are still limitations in acclimatization protocols, especially concerning in plant development and the reduction of dwell time of the plantlets (González-
Olmedo et al., 2005) as in vitro plantlets are very fragile due to plantlets sensitivity to sudden environmental changes, especially in transferring process from in vitro culture vials to ex vitro conditions, and later from the greenhouse to field plantation (Mengesha et al., 2013). The risk of plantlets to become wilt when transferred to ex vitro conditions is high due to the transfer shock (Pospóšilová et al., 1999). This situation will eventually lead to plantlets damage due to the low humidity, high irradiation levels, water deficit due to weak root hydraulic conductivity and low root-state connection (Fila et al., 1998). Therefore, the needs of plantlets to adapt the harsh and uncontrolled ex vitro environment of a greenhouse or the field are very necessary. The transitional phase of plant development is called acclimatization or hardening (Rodriguez et al., 2008). Normally, the air humidity temperature, airflow, and irradiation level were gradually lowered to enhance the survival of plantlets in ex vitro conditions (Pospóšilová et al., 1999). Therefore, the ultimate success of plantlets depends on the successful plant transfer and establishment under ex vitro conditions.

Thus, this paper study aims to determine the effect of in vitro regeneration of pineapple (Ananas comosus L. Merr.) var. MD2 by adding coconut water as natural growth regulators and optimum sucrose concentration needed as well as to compare the effect of different sucrose concentration towards in vitro regeneration of MD2. The application of the different fertilizer mechanism on the growth performance of MD2 plantlets during acclimatization was also identified in this study.

\section{Materials and methods}

This study was conducted at the postgraduate laboratory and greenhouse of Faculty of Plantation and Agrotechnology, Universiti Teknologi MARA (UiTM) Selangor, Kampus Puncak Alam, Malaysia.

\subsection{In vitro regeneration of pineapple var. MD2}

\subsubsection{MS medium preparation for coconut water and sucrose concentration}

Plant tissue culture media for coconut water was prepared by adding the $4.40 \mathrm{~g} / \mathrm{L}$ MS nutrient powder (Murashige and Skoog, 1967), $30.00 \mathrm{~g} / \mathrm{L}$ sucrose and $8.00 \mathrm{~g} / \mathrm{L}$ solidifying agar (Technical Agar No.3) with four different coconut water volume (00.00, 10.00, 15.00, 20.00 and $25.0 \mathrm{~mL} / \mathrm{L} \mathrm{v} / \mathrm{v})$. Meanwhile, media for sucrose concentration effects was prepared by adding the $4.40 \mathrm{~g} / \mathrm{L}$ MS nutrient powder, $8.00 \mathrm{~g} / \mathrm{L}$ of solidifying agar (Technical Agar No.3) with different sucrose concentrations of $00.00,10.00,20.00,30.00$ and $40.00 \mathrm{~g} /$ L. Each treatment was supplemented with $2.00 \mathrm{mg} / \mathrm{L}$ 
BAP and $1.00 \mathrm{mg} / \mathrm{L}$ NAA. All culture media were adjusted to $\mathrm{pH} 5.80$ using $1 \mathrm{M} \mathrm{NaOH}$ or $1 \mathrm{M} \mathrm{HCl}$ prior to autoclaving at $121^{\circ} \mathrm{C}$ for 20 mins.

\subsubsection{Plant material and surface sterilization method}

A healthy and young sucker of pineapples var. MD2 was obtained from NAZA Plantation, Johor, Malaysia. The leaves and roots of sucker were removed and rinsed under running tap water for 30 minutes. Then, the surface sterilization method of explant was conducted under laminar airflow cabinet. The explants were immersed into $50 \%(\mathrm{v} / \mathrm{v})$ sodium hypochlorite $(\mathrm{NaOCl})$ and a few drops of Tween 20 for 5 mins and swirl swiftly. Next, the explants were rinsed off using autoclaved distilled water for three times and 5 mins each rinse. The clean and sterile explants were subsequently dried off on autoclave tissue towel for 10 mins to remove any excess moisture. Lastly, the explants were trimmed to the size of $5 \mathrm{~mm}^{3}$ and were initiated onto the medium with ten replications for each treatment.

\subsubsection{Culture initiation and culture establishment}

The explants were cultured for three months and subculture at a monthly interval. The explants were maintained in a culture room at temperature $25 \pm 2.0^{\circ} \mathrm{C}$ under $16 \mathrm{hrs}$ of photoperiod. The pineapple plantlets growths were observed and data on the number of shoots were collected. The collected data were statistically analyzed using one-way analysis of variance (ANOVA) by SPSS program at the $5 \%$ level of significance and Microsoft Excel.

\subsection{Acclimatization of pineapple var. MD2}

2.2.1 Plant materials for transplanting and primary stage acclimatization of clonal pineapple

The planting medium for primary acclimatization was prepared according to Abebe et al. (2003) with slight modification. The soil mixture comprises of topsoil, coco peat, and sand at ratio 1:2:1. Coco peat was used to replace the coffee husk from the previous method. Next, the soil mixtures were autoclaved for two hours and filled onto the seedling tray for twenty replications. Then, the clonal pineapples were thoroughly washed under running tap water to remove solidified nutrient agar from the roots and dipped in $2.00 \mathrm{~g} / \mathrm{L}$ fungicide for $1 \mathrm{~min}$ before planting. The cultivated clonal pineapples were assigned according to the treatment in a complete randomized design inside a room with a temperature of $20-25^{\circ} \mathrm{C}$. Watering is done twice a day. Fertilizer was applied after two weeks of planting clonal pineapple with $0.30 \mathrm{~g}$ of compound fertilizer, NPK green (15:15:15). Next, the six-week-old clonal pineapples were sprayed with $5.00 \mathrm{~g} / \mathrm{L}$ foliar fertilizer with seven (7) days interval. Foliar fertilizer is a mixture of several compounds according to the manual of pineapple management by Malaysian Pineapple Industry Board (2007). The primary acclimatization of clonal pineapple was grown for two months before transplanted to the secondary acclimatization.

\subsubsection{Secondary stage acclimatization of clonal pineapple}

The secondary stage of acclimatization was conducted at the greenhouse, Universiti Teknologi MARA (UiTM) Selangor, Kampus Puncak Alam, Malaysia. Polybags (16" x 16") were filled with a soil mixture of topsoil, sand, and compost at ratio 2:1:2. The clonal pineapples in seedling trays from primary stage acclimatization were transplanted into polybags. The watering activity was done twice a day. Fertilizing activity is done by using the same formulation of foliar fertilizer from the primary stage acclimatization where the foliar fertilizer was applied 2 days interval for 30 days. After a month, the fertilizer was changed into two types where each type of fertilizer had different mechanism acted as treatments. The fertilizers were standard compound fertilizer, NPK (15:15:15) and controlled-release fertilizer (AJIB CRF), NPKMg (10:5:18:3). The dosage used per clonal pineapple was $20.00 \mathrm{~g}$, recommended by the fertilizer manufacturer for pineapple. This experiment was done in a complete randomized design with ten (10) replications for each treatment.

\subsubsection{Data collection and statistical analysis}

The collection of data for primary acclimatization was collected for two months and secondary acclimatization for four months. The parameters were observed and collected for six months. The data were analyzed according to research by González et al. (2018) and Mengesha et al. (2013) using the SPSS program.

\section{Results and discussion}

\subsection{Effect of coconut water on production in vitro shoot of pineapple}

The number of shoots from pineapple cultures for each treatment had increased significantly after six weeks of culture (Figure 1). Table 1 shows the mean value for number of shoots in all treatments. Sample in medium supplemented with $20.0 \mathrm{~mL} / \mathrm{L}$ of coconut water shows the highest mean number of shoots $(45.33 \pm 7.56)$ followed by culture supplemented with $25.00 \mathrm{~mL} / \mathrm{L}$ coconut water $(43.83 \pm 7.31)$. Based on the ANOVA result, the mean value for media supplemented with coconut water of $20.00 \mathrm{~mL} / \mathrm{L}$ and $25.00 \mathrm{~mL} / \mathrm{L}$ showed only a small difference of mean value and significance value. Hence, this indicates that coconut water positively 
affects the shoot production. Thus, the null hypothesis is accepted as $20.00 \mathrm{~mL} / \mathrm{L}$ coconut water was the optimum amount for pineapple tissue culture production. This is because coconut water contains eleven types of naturally occurring cytokinin. High cytokinin concentrations tend to induce adventitious shoots faster than other parts of the clonal plantlets (Kyte and Kleyn, 1996) where all the shoots emerged from the bud plantlets of the clonal pineapple culture or newly differentiated adventitious buds.

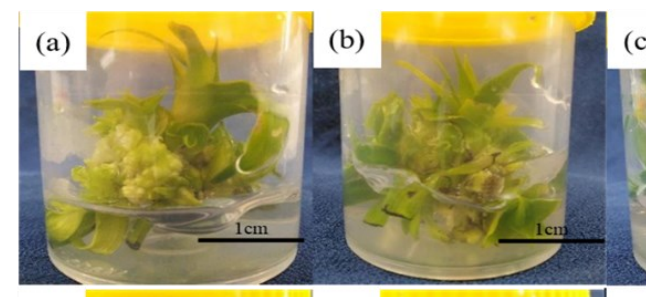

(c)

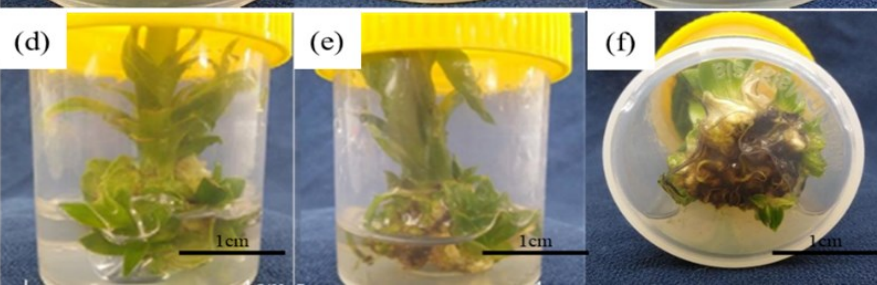

Figure 1. In vitro regeneration of pineapple variety MD2 were cultured on MS media supplemented with coconut water (a) 0.00 , (b) 10.00 , (c) 15.00 , (d) 20.00 , and (e) $25.00 \mathrm{~mL} / \mathrm{L}$. In vitro pineapple rooting in $25.00 \mathrm{~mL} / \mathrm{L}$ coconut water after 6 weeks (f).

Table 1. The mean value for number of shoots (Ananas comosus L. Merr var. MD2) emerged in MS media supplemented with different amount of coconut water and sucrose concentration.

\begin{tabular}{lcc}
\hline Treatment & Amount & Number of shoots \\
\hline & 0 & $30.33 \pm 5.06$ \\
Coconut water $(\mathrm{mL} / \mathrm{L})$ & 10 & $32.50 \pm 5.42$ \\
& 15 & $18.67 \pm 3.11$ \\
& 20 & $45.33 \pm 7.56$ \\
& 25 & $43.83 \pm 7.31$ \\
\hline & 0 & $3.25 \pm 0.0 .37$ \\
Sucrose concentration $(\mathrm{g} / \mathrm{L})$ & 10 & $32.2 \pm 5.27$ \\
& 20 & $36.63 \pm 4.88$ \\
& 30 & $47.25 \pm 10.81$ \\
& 40 & $30.25 \pm 4.44$ \\
\hline
\end{tabular}

3.2 Effect of coconut water on in vitro rooting of pineapple

In vitro roots were emerged from one of the replications of $25.00 \mathrm{~mL} / \mathrm{L}$ after six weeks of culture initiation. The pineapple plantlets exhibit a clear characteristic of bigger shoots compared to the other replications as well as browning at the base and root buds can be clearly seen. The texture of the agar medium also becomes sleet after 60 days. The reason for the rooting of the pineapple is due to the presence of NAA in the media which act as auxin that induced rooting in pineapple plantlets. The synthetic plant hormone $(2.00$ $\mathrm{mg} / \mathrm{L}$ BAP, $1.00 \mathrm{mg} / \mathrm{L}$ NAA) added and naturally occurring auxin growth regulator components inside coconut water might trigger the rooting formation in pineapple tissue culture. Moreover, larger shoot size, longer incubation period, the optimum amount of sucrose $(30.0 \mathrm{~g} / \mathrm{L})$, and culture media with adjusted $\mathrm{pH}$ 5.5-5.8 contributes to a good environment for rooting (Mohajer et al., 2015).

\subsection{Effect of sucrose concentration on the production of in vitro shoot of pineapple}

Table 1 shows the mean value for number of shoots produced in treatment supplemented with coconut water and sucrose concentration. Control treatment $(00.00 \mathrm{~g} / \mathrm{L}$ sucrose) resulted in the lowest mean value for production of in vitro pineapple shoots among other treatments due to insufficient carbon source to supply carbon needed by the culture system for cell growth, development and morphogenesis (Javed and Ikram, 2008). Meanwhile, the highest mean value for the number of shoots was in $30.00 \mathrm{~g} / \mathrm{L}$ sucrose with $47.25 \pm 10.81$ followed by 20.00 $\mathrm{g} / \mathrm{L} \quad(36.63 \pm 4.88)$, treatment $10.00 \mathrm{~g} / \mathrm{L}$ sucrose $(32.2 \pm 5.270)$ and finally treatment $40.00 \mathrm{~g} / \mathrm{L}$ sucrose with a mean value of $30.25 \pm 4.44$. Figure 2 shows the differences in culture conditions of different treatments.

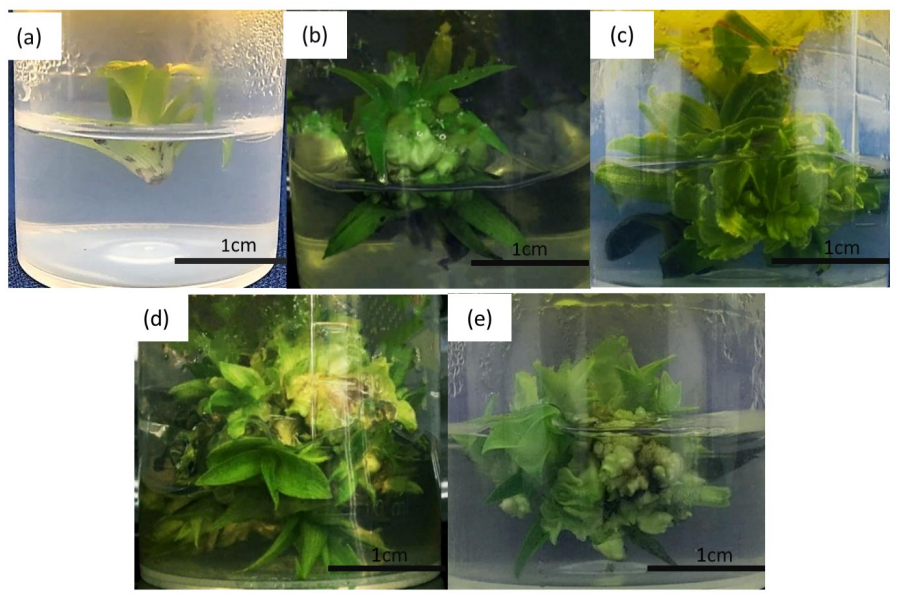

Figure 2. In vitro regeneration of pineapple variety MD2 were cultured on MS media with (a) 0.0 , (b) 10.0 , (c) 20.0, (d) 30.0, and (e) $40.0 \mathrm{~g} / \mathrm{L}$ of sucrose.

Sucrose as a carbon source, if supplemented at an appropriate amount, will help and enhance the regeneration of explant. MD2 cultured on media supplemented with $30.00 \mathrm{~g} / \mathrm{L}$ sucrose has the highest mean value for both shoots. Nelson et al. (2015) reported that $30.00 \mathrm{~g} / \mathrm{L}$ sucrose produced shoot with the highest weight. Muslihatin and Ratnadewi (2012) stated that the optimum concentration of sucrose for the sago palm was found to be $30.00 \mathrm{~g} / \mathrm{L}$. In addition, optimum sucrose treatment boosts the percentage of pineapple proliferation and the number of shoots produced (El, Zaied and Saleh, 2010). Nelson et al. (2015) found that plantlets in the medium with $30.00 \mathrm{~g} / \mathrm{L}$ sucrose concentration is also notably taller than other sucrose 
concentrations. Furthermore, the in vitro leaves are rapidly generated and multiplied due to the concentration of the cytokinin (BAP) used in the culture media is higher compared to auxin (NAA). Cytokinin promotes cell division and shoots proliferation as reported where $2.00 \mathrm{mg} / \mathrm{L}$ BAP produced the highest number of shoots in pineapple (Al-Saif et al., 2011).

\subsection{Growth performance of clonal pineapple secondary acclimatization}

The pineapple plantlets were transferred into 16 " $\mathrm{x}$ 16 " polybag filled with soil mix composing of topsoil, coco peat, and sand (Figure 3). The mean value for morphological variables of plantlets of Ananas comosus L. Merr var. MD2 in primary acclimatization and secondary acclimatization applied with compound fertilizer and controlled-release fertilizer (AJIB CRF) were displayed in Table 2. The clonal pineapple should be turgid, vivacious, very well acclimatized, and easy for handling to tolerate transportation and field shocks (Pospóšilová et al., 1999). Although the primary acclimatization plantlets are efficient for handling process and require less cost of transportation, they are in poor condition to get through the ex-vivo extreme surroundings due to poor root stem connection, poor cuticle development, high stomatal conductance, and poor photosynthesis ability (Fila et al., 1998).

Therefore, secondary hardening is a crucial part to ensure the success of using in vitro regenerated pineapple as the source of planting material. Controlledrelease fertilizer contained a balance micronutrient and macronutrient that firstly developed in Malaysia using the Polymer Coated Agglomeration Technology (PCAT) from Germany to increase the absorbent of nutrients efficiently and reduced the nutrient leaching caused by heavy rain. The polymer-coated on fertilizer is hydrophobic that made it dissolved the nutrient controllably (Diversatech, 2019). The primary acclimatization for MD2 pineapple plantlets resulted in a very high rate of survival rate and shown a uniform growth performance for each replicate. Further hardening for these plantlets was continued to secondary acclimatization.
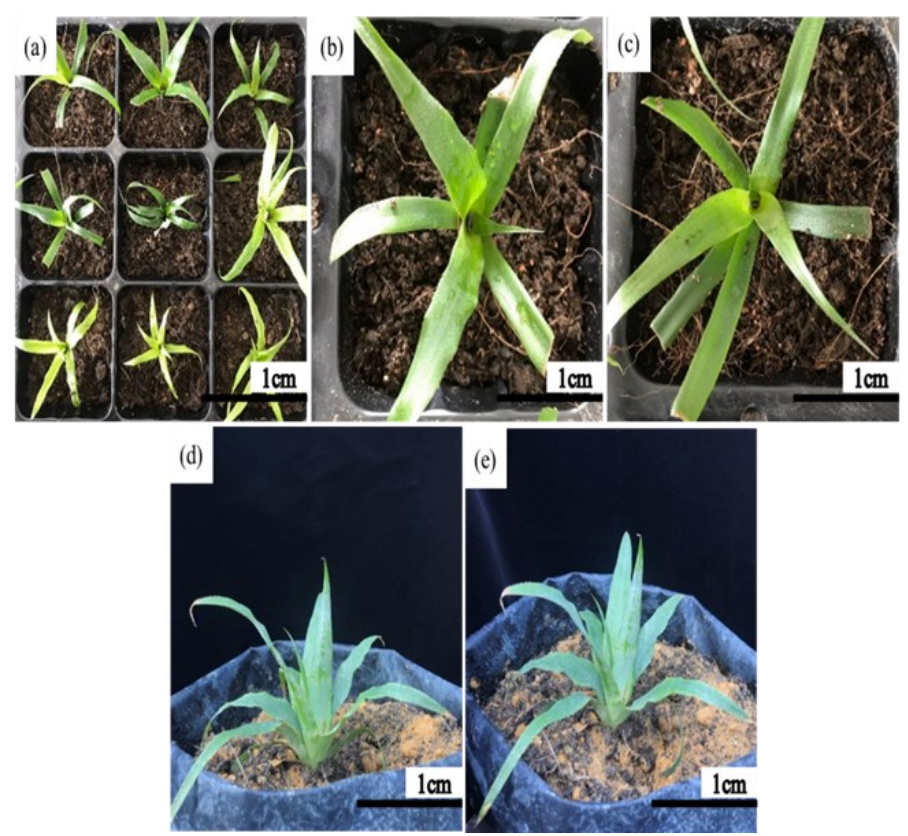

Figure 3 . The primary acclimatization of clonal pineapple (a, b, and c) after thirty (30) days prior to be transplanted into polybags in the greenhouse after three (3) months (d, e).

The data collection on secondary acclimatization showed that the mean value of leaves length $(\mathrm{cm} /$ leaf) for controlled-release fertilizer (AJIB CRF) and compound fertilizer were $6.00 \pm 1.04$ and $3.43 \pm 0.80$ respectively. Treatment with Controlled-release fertilizer resulted significantly higher than the compound fertilizer with a difference of $2.47 \mathrm{~cm} /$ leaf and was significantly higher than compound fertilizer. The mean value for

Table 2. The mean value for morphological variables of plantlets of Ananas comosus L. Merr var. MD2 in primary acclimatization and secondary acclimatization applied with compound fertilizer and controlled-release fertilizer (AJIB CRF).

\begin{tabular}{|c|c|c|c|c|}
\hline Treatment & Acclimatisation Stage & Leaves Length $(\mathrm{cm})$ & Leaves Number & Survival Rate $(\%)$ \\
\hline Compound Fertilizer & Secondary & $3.43 \pm 0.80^{\mathrm{a}}$ & $2.75 \pm 0.63^{\mathrm{a}}$ & $0.70 \pm 0.07^{\mathrm{a}}$ \\
\hline $\begin{array}{c}\text { Controlled-release } \\
\text { Fertilizer (AJIB CRF) }\end{array}$ & (12-24 weeks) & $6.00 \pm 1.04^{\mathrm{b}}$ & $5.48 \pm 0.96^{\mathrm{b}}$ & $0.98 \pm 0.02^{\mathrm{b}}$ \\
\hline No treatment & $\begin{array}{l}\text { Primary } \\
(0 \text { weeks })\end{array}$ & $5.45 \pm 1.22^{\mathrm{c}}$ & $4.20 \pm 0.00^{\mathrm{c}}$ & $1.00 \pm 0.00^{\mathrm{c}}$ \\
\hline Compound Fertilizer & $\begin{array}{l}\text { Secondary } \\
\text { ( } 24 \text { weeks) }\end{array}$ & $6.60 \pm 1.54^{\mathrm{c}}$ & $6.10 \pm 1.48^{c}$ & $0.70 \pm 0.15^{\mathrm{d}}$ \\
\hline No treatment & $\begin{array}{l}\text { Primary } \\
(0 \text { weeks })\end{array}$ & $7.87 \pm 0.96^{\mathrm{e}}$ & $5.40 \pm 0.60^{\mathrm{e}}$ & $1.00 \pm 0.00^{\mathrm{e}}$ \\
\hline $\begin{array}{c}\text { Controlled-release } \\
\text { Fertilizer (AJIB CRF) }\end{array}$ & $\begin{array}{l}\text { Secondary } \\
\text { (24 weeks) }\end{array}$ & $11.78 \pm 1.46^{\mathrm{e}}$ & $11.60 \pm 1.41^{\mathrm{e}}$ & $0.90 \pm 0.10^{\mathrm{f}}$ \\
\hline
\end{tabular}

Different letter denotes significant differences at $\mathrm{p}<0.05$. a, b represents significant of different treatments on secondary stage. $\mathrm{c}, \mathrm{d}$ represents significant between stages for compound fertilizer. e, f represents significant between stages for controlled-release fertilizer. 
clonal pineapple leaves in controlled-release fertilizer (AJIB CRF) and compound fertilizer were $5.48 \pm 0.96$ and 2.75 respectively with a difference of 2.73 leaves per clonal pineapple. The survival rate for compound fertilizer is $70 \%$ and was significantly lower than the controlled-release fertilizer (CRF) at $90 \%$ with a difference of $20 \%$ in survival rate.

Different types of fertilizers were employed for growing clonal pineapple. Similar to planting medium, types of fertilizer also affect plant growth performance (Vasane and Kothari, 2006). The hardening process of clonal pineapple was evaluated on the different types of fertilizers showed that Controlled-release fertilizer (AJIB CRF) had better plant performance and higher survival rate. Hence, Controlled-release fertilizer (AJIB CRF) increased the leaves length $(\mathrm{cm})$, leaves number, and the survival rate of plantlets compared to the standard compound fertilizer.

\subsection{Morphological analysis of acclimatized clonal pineapple}

In vitro regenerated pineapple plantlets were planted into seedling trays filled with topsoil, coco peat, and sand. The soil mix was altered from the previous study by Mengesha et al. (2013) who reported in cocopeat $100 \%$ of survival rate was obtained compared to soil mix composing topsoil, coffee husk, and sand in 1:2:1 with $90 \%$ of survival rate. The altered soil mixture has more organic matter and an equal proportion of soil and sand. This improves soil aeration and reduces water retention for better root growth, which comprises improved root and shoot-root connection for hydraulic conductivity (Fila et al., 1998). This prompted to a better survival rate and plant performance than previously reported for soil mix (Abebe et al., 2003). Coco peat production has impacts on the ecological that are creating concerns for the long-term availability of peat as the primary acclimatization substrate (Ilahi and Ahmad, 2017). Therefore, due to local availability, cheap price, reusability, and ecological friendly, coco peat is found to be a good substrate for large scale preliminary acclimatization of in vitro clonal pineapple in Malaysia.

Table 2 also shows the mean value for morphological variables changes of clonal pineapples in primary acclimatization and secondary acclimatization by compound fertilizer. The leaves length $(\mathrm{cm} / \mathrm{leaf})$ for primary acclimatization with $5.45 \pm 1.22$ were not significant with secondary acclimatization, $6.60 \pm 1.54$ (cm/leaf). Furthermore, the result for leaves number for secondary acclimatization with $6.10 \pm 1.48$ (leaf/plantlet) was also not significant with primary acclimatization, $4.20 \pm 0.00$ (leaf/plantlet), with a difference of 1.90 (leaf/ plantlet). However, the survival rate for primary acclimatization is $100 \%$ were significantly higher compared to secondary acclimatization with only $70 \%$ of survival rate.

Next, the mean value for morphological variables changes of clonal pineapples in primary acclimatization and secondary acclimatization by controlled-release fertilizer (AJIB CRF), NPKMg (10:5:18:3). It was found that the mean for leaves length $(\mathrm{cm})$ for primary acclimatization with $7.87 \pm 0.96$ (cm/leaf) were not significant, with slightly lower than the secondary acclimatization, $11.78 \pm 1.46(\mathrm{~cm} /$ leaf). Furthermore, the result for leaves number for secondary acclimatization with $11.60 \pm 1.41$ (leaf/plantlet) also not significant, but slightly higher than primary acclimatization, $5.40 \pm 0.60$ (leaf/plantlet). However, the survival rate for primary acclimatization is $100 \%$ were significantly higher than the secondary acclimatization with a $90 \%$ survival rate.

Leaves initially were shorter and narrower when plantlets were first transferred from culture room to the primary acclimatization surrounding. The low light levels during in vitro culture likely caused some etiolation of the leaves (Villalobo et al., 2016). However, by the end of observation, the leaves have gradually become longer and wider. During the acclimatization process, the transpiration is gradually reduced as stomata become functional, and cuticular water loss declined, the observation is consistent (Herrera, 2009). At the point when stomatal and cuticular transpiration rates on in vitro leaves are high, it is hard to keep plant turgidity as it was transplanted to ex vitro (Seon et al., 2000). Although the length and the diameter of leaves for both treatments not demonstrating a noteworthy extraordinary, they were increasing and may show the plantlets were adjusted to the new conditions during acclimatization stage and possibly of plants having Crassulacean acid metabolism (Zhu et al., 2002). The impacts of addiction in light intensity and the slow decrease of relative humidity at the beginning period were shown in pineapple plantlets (Yanes et al., 2000). Batagin et al. (2009) found out an increase in cuticle thickness, on wavy contours of epidermal cells, and on the distribution and quantity of mesophyll, fibres were observed during acclimatization process, evidencing the light condition's interference in morphological characteristics of the pineapple plantlets. According to Gonzalez-Olmedo et al. (2005), in vitro propagation of pineapple has shown that light is the factor with more effect on plant quality and during the acclimatization stage; it will give better agronomic and anatomical change. During the secondary acclimatization phase, plantlets implemented by using controlled-release fertilizer (AJIB CRF) show a higher mean for all parameters. The main cause for this result is an optimum 
nutrient that can be absorbed by the plant as the coating on Controlled-release fertilizer (AJIB CRF) is hydrophobic that made it dissolved the nutrient controllably (Diversatech, 2019). Clonal pineapple survival was significantly greater in the controlledrelease fertilizer (AJIB CRF) treatment compared the compound fertilizer. For the most part, it is perceived that natural change during in vitro to ex vitro conditions cause stress in plants. According to Bat'ková et al. (2008) and Carvalho et al. (2006), this stress expressed in terms of accumulation of abscisic acid (ABA), proline, and reactive oxygen species. Notwithstanding, results on in vitro have demonstrated that it is conceivable to influence the carbon metabolism by changing the surrounding temperature during the light and the dim period (Nievola et al., 2005).

\section{Conclusion}

In conclusion, coconut water effects the number of in vitro shoot production of pineapple. MS medium supplemented with $20.00 \mathrm{~mL} / \mathrm{L}$ coconut water and $30.00 \mathrm{~g} / \mathrm{L}$ sucrose showed the highest mean number of shoots produced. The controlled-release fertilizer is the most suitable fertilizer for optimum performance of clonal pineapple during acclimatization process.

\section{Conflict of interest}

The authors declare no conflict of interest.

\section{Acknowledgments}

This study was financially supported by the 600 IRMI/FRGS 5/3 (057/2019) facilitated by Research Management Institute, Universiti Teknologi MARA (UiTM) Shah Alam, Selangor, Malaysia.

\section{References}

Abebe, Z., Tefera, W., Fellipe, M., Teressa, A. and Mengesha, A. (2003). In vitro multiplication of pineapple (Ananas comosus (L.)) and cardamom (Elletaria cardamomum). Ethiopia. Proceeding of the Second Biennial Conference of Ethiopian Horticultural Science Society, 22 - 23 January 2009. Addis Ababa, Ethopia.

Agampodi, V.A. and Jayawardena, B. (2009). Effect of coconut (Cocos nucifera L.) water extracts on adventitious root development in vegetative propagation of Dracaena purplecompacta L. Acta Physiologiae Plantarum, 31(2), 279-284. https:// doi.org/10.1007/s11738-008-0230-y

Akin-idowu, P.E. and Ibitoye, D.O. (2014). Influence of medium type and growth regulators on in vitro micropropagation of pineapple (Ananas comosus (L.), var. Smooth Cayenne). African Journal of Plant Science, 8(9), 450-456. https://doi.org/10.5897/ AJPS2014.1184

Al-Saif, A.M., Hossain, A.B.M.S. and Taha, R.M. (2011) Effect of Benzylaminopurine and Naphtalene Acetic Acid on Proloferation and Shoot Growth of Pineapple (Ananas comosus L. Merr.) in vitro. African Journal of Biotechnology, 10(27), 52915295. https://doi.org/10.5897/AJB1 1.370

Awal, A., Nor Fazilah, N., Azvin, M.P., Najwa, M., Shamsiah, A. and Norrizah, J.S. (2011). Micropropagation of Pineapple (Ananas comosus L. Merr. 'Josapine'). Acta Horticulturae, 923, 163-168 https://doi.org/10.17660/ActaHortic.2011.923.23

Batagin, K.D., de Almeida, C.V., Tanaka, F.O. and Almeida, M.D. (2009). Morphological alterations in leave of micropropagated pineapple plants var. IAC" Gomo-de-mel" acclimatizated in different conditions of luminosity. Acta Botanica Brasilica, 23(1), 85-92. https://doi.org/10.1590/S0102-33062009000100011

Bat'ková, P., Pospíšilová, J. and Synkova, H. (2008). Production of reactive oxygen species and development of antioxidative systems during in vitro growth and ex vitro transfer. Biologia Plantarum, 52 (3), 413-422. https://doi.org/10.1007/s10535-0080085-5

Carvalho, L.C., Vilela, B.J., Vidigal, P., Mullineaux, P.M. and Amâncio, S. (2006). Activation of the ascorbate-glutathione cycle is an early response of micropropagated Vitis vinifera $\mathrm{L}$. explants transferred to ex vitro. International Journal of Plant Sciences, 167(4), 759-770. https:// doi.org/10.1086/503919

Diversatech, F. (2019). AJIB CRF. Retrieved from myjbaja website: http://myjbaja.blogspot.com/p/ajibcrf.html

El, A., Zaied, G.N.M.A. and Saleh, M.A. (2010). A comparative Study on Different Carbon Source Concentrations and Gelling A Gent On In vitro Proliferation of Pineapple (Ananas comosus), 8(5), 127-130.

Fila, G., Ghashghaie, J., Hoarau, J. and Cornic, G. (1998). Photosynthesis, leaf conductance and water relations of in vitro cultured grapevine rootstock in relation to acclimatisation. Physiologia Plantarum, 102(3), 411-418. https://doi.org/10.1034/j.13993054.1998.1020309.x

González, G.Y.L., Legrá, Y.P., Rodríguez-Escriba, R.C., Borroto, L.S.P., Borrero, L.N., Mendoza, J., Cardoso, D., Alonso, A., Sanchez, R.R. and Gonzalez-Olmedo, J.L. (2018). Foliar fertilization of 
'MD 2' pineapple plants (Ananas comosus var. comosus) during the acclimatization phase. Leuven, Belgium: Pineapple Working Group, International Society for Horticultural Science

González, G.Y.L., Rodríguez-Escriba, R.C., Martínez, R.E.I., Pérez, L.S., Borroto, Y.L.D., Sánchez, R.R. and González-Olmedo, J.L. (2016). Response of 'MD-2' Pineapple Plantlets (Ananas comosus var. comosus) to a Controlled Release Fertilizer during the Acclimatization Stage. Leuven, Belgium: Pineapple Working Group, International Society for Horticultural Science

González, R., Laudat, T., Arzola, M., Méndez, R., Marrero, P., Pulido, L.E., DIbut, B. and Lorenzo, J.C. (2011). Effect of Azotobacter chroococcum on in vitro pineapple plants' growth during acclimatization. In Vitro Cellular and Developmental Biology-Plant, 47, 387-390. https:// doi.org/10.1007/s11627-010-9334-3

González-Olmedo, J.L., Fundora, Z., Molina, L.A., Abdulnour, J., Desjardins, Y. and Escalona, M. (2005). New contributions to propagation of pineapple (Ananas comosus L. Merr) in temporary immersion bioreactors. In vitro Cellular and Developmental Biology-Plant, 41(1), 87-90. https:// doi.org/10.1079/IVP2004603

Hamid, N.S., Bukhori, M.F.M. and Jalil, M. (2013). Direct and indirect plant regenerations of pineapple var. MD2 (Ananas comosus L.). Malaysian Applied Biology, 42(1), 61-66.

Herrera, A. (2009). Crassulacean acid metabolism and fitness under water deficit stress: if not for carbon gain, what is facultative CAM good for?. Annals of Botany, 103(4), 645-653. https://doi.org/10.1093/ $\mathrm{aob} / \mathrm{mcn} 145$

Hossain, M.F. (2016). World pineapple production: An overview. African Journal of Food, Agriculture, Nutrition and Development, 16(4), 11443-11456. https://doi.org/10.18697/ajfand.76.15620

Hossain, M.F., Akhtar, S. and Anwar, M. (2015). Nutritional Value and Medicinal Benefits of Pineapple. International Journal of Nutrition and Food Sciences, 4(1), 84-88. https://doi.org/10.11648/ j.ijnfs.20150401.22

Ilahi, W.F.F. and Ahmad, D. (2017). A study on the physical and hydraulic characteristics of cocopeat perlite mixture as a growing media in containerized plant production. Sains Malaysiana, 46(6), 975-980. https://doi.org/10.17576/jsm-2017-4606-17

Javed, F. and Ikram, S. (2008). Effect of sucrose induced osmotic stress on callus growth and biochemical aspects of two wheat genotypes. Pakistan Journal of
Botany, 40(4), 1487-1495.

Kyte, L. and Kleyn, J. (1996). Plants from test tubes: An introduction to micropropagation. $3^{\text {rd }}$ ed. USA: Timber Press.

Liu, L.J., Rosa-Márquez, E. and Lizardi, E. (1989). Smooth leaf (spineless) Red Spanish pineapple (Ananas comosus) propagated in vitro. The Journal of Agriculture of the University of Puerto Rico, 73 (4), 301-311. https://doi.org/10.46429/ jaupr.v73i4.6308

Malaysian Pineapple Industry Board (MPIB) (2007). Manual: Management of pineapple crop (2007). Johor Bharu, Johor, Malaysia: Malaysian Pineapple Industry Board.

Mengesha, A., Ayenew, B. and Tadesse, T. (2013). Acclimatization of in vitro propagated pineapple (Ananas comosus (L.), var. smooth cayenne) plantlets to ex vitro condition in Ethiopia. American Journal of Plant Sciences, 4, 317-323. https:// doi.org/10.4236/ajps.2013.42042

Mohajer, S., Taha, R. and Adel, M. (2015). In Vitro Environmental Factors Controlling Root Morphological Traits of Pineapple (Ananas comosus L. Merr.). World Academy of Science, Engineering and Technology, 9(11), 1063-1066.

Murashige, T. and Skoog, F. (1962). A revised medium for rapid growth and bioassays with tobacco tissue cultures. Physiologia Plantarum, 15(3), 473-497. https://doi.org/10.1111/j.1399-3054.1962.tb08052.x

Nelson, B.J., Asare, P.A. and Junior, R.A. (2015). In vitro Growth and Multiplication of Pineapple under Different Duration of Sterilization and Different Concentrations of Benzylaminopurine and Sucrose. Biotechnology, 14(1), 35-40. https:// doi.org/10.3923/biotech.2015.35.40

Nievola, C.C., Kraus, J.E., Freschi, L., Souza, B.M. and Mercier, H. (2005). Temperature determines the occurrence of CAM or C 3 photosynthesis in pineapple plantlets grown in vitro. In Vitro Cellular and Developmental Biology-Plant, 41, 832. https:// doi.org/10.1079/IVP2005694

Peixe, A., Raposo, A., Lourenço, R., Cardoso, H. and Macedo, E. (2007). Coconut water and BAP successfully replaced zeatin in olive (Olea europaea L.) micropropagation. Scientia Horticulturae, 113 (1). 1-7. https://doi.org/10.1016/ j.scienta.2007.01.011

Pospóšilová, J., Tichá, I., Kadleček, P., Haisel, D. and Plzáková, $\breve{S}$. (1999). Acclimatization of micropropagated plants to ex vitro conditions. Biologia Plantarum, 42(4), 481-497. https:// doi.org/10.1023/A:1002688208758 
Rodriguez, R., Aragon, C.E., Escalona, M., GonzalezOlmedo, J.L. and Desjardins, Y. (2008). Carbon metabolism in leaves of micropropagated sugarcane during acclimatization phase. In Vitro Cellular and Developmental Biology-Plant, 44(6), 533-539. https://doi.org/10.1007/s11627-008-9142-1

Seon, J.-H., Cui, Y.-Y., Kozai, T. and Paek, K. (2000). Influence of in vitro growth conditions on photosynthetic competence and survival rate of Rehmannia glutinosa plantlets during acclimatization period. Plant Cell, Tissue and Organ Culture, 61, 135. https://doi.org/10.1023/ A: 1006473223286

Sumaryono, S., Muslihatin, W. and Ratnadewi, D. (2012). Effect of Carbohydrate Source on Growth and Performance of In vitro Sago Palm (Metroxylon sagu Rottb.) Plantlets. HAYATI Journal of Biosciences, 19(2), 88-92. https://doi.org/10.4308/ hjb.19.2.88

Thalib, A.A., Tong, P.S. and Ng, C. (2015). The MD2 'Super Sweet' pineapple (Ananas comosus). Utar Agriculture Science Journal. 1(4), 2-3. (2017, April 9). Retrieved from Malaysia Pineapple Industrial Board website :http://www.mpib.gov.my/web/guest/ soalanlazim?

p_p_id $=56 \_I N S T A N C E \_$_e5uNandp_p_lifecycle $=0$ an dp_p_state $=$ normalandp $\_p \_$mode $=$viewandp $\_p \_c o l \_i$ $\mathrm{d}=$ column6andp_p_col_count $=1$ andpage $=1$.

Vasane, S.R. and Kothari, R.M. (2006). Optimization of secondary hardening process of banana plantlets (Musa paradisiaca L. var. grandnain). Indian Journal of Biotechnology, 5(3), 394 - 399.

Villalobo, A., González, J., Santos, R. and Rodríguez, R. (2012). Morpho-physiological changes in pineapple plantlets [Ananas comosus (L.) Merr.] during acclimatization. Ciência e Agrotecnologia, 36(6), 624-630. https://doi.org/10.1590/S141370542012000600004

Yanes, E., González-Olmedo, J.L. and Rodríguez, R. (2000). Light management during acclimatization of Pineapple (Ananas comosus (L.) Merr.) var. Cayena lisa 'Serrana' Vitroplants. Leuven, Belgium: Pineapple Working Group, International Society for Horticultural Science

Yong, J.W.H., Ge, L., Ng, Y.F. and Tan, S.N. (2009). The chemical composition and biological properties of coconut (Cocos nucifera L.) water. Molecules, 14 (12), 5144-5164. https://doi.org/10.3390/ molecules 14125144

Zhu, J., Bartholomew, D.P. and Goldstein, G. (2002, April). Photosynthetic gas exchange and water relations during drought in 'Smooth Cayenne' pineapple (Ananas comosus (L.) Merr.) grown under ambient and elevated $\mathrm{CO}_{2}$ and three day/night temperatures. Acta Horticulturae, 666, 161-173. https://doi.org/10.17660/ActaHortic.2005.666.15 